\title{
Gunshot wounds to the head: racial disparities in inpatient management and outcomes
}

\author{
Ryan G. Chiu, BS, Angelica M. Fuentes, BS, and Ankit I. Mehta, MD \\ Department of Neurosurgery, University of Illinois at Chicago, Illinois
}

\begin{abstract}
OBJECTIVE Several studies have indicated that racial disparities may exist in the management and outcomes of acute trauma care. One segment of trauma care that has not been as extensively investigated, however, is that of cranial trauma care. The goal of this study was to determine whether significant differences exist among racial and ethnic groups in various measures of inpatient management and outcomes after gunshot wounds to the head (GWH).
\end{abstract}

METHODS In this study, the authors used the Nationwide (National) Inpatient Sample (NIS) to investigate all-cause mortality, receipt of surgery, days from admission to initial intervention, discharge disposition, length of hospital stay, and total hospital charges of those with GWH from 2012 to 2016. A 1:1 propensity score-matched analysis was conducted to evaluate the effect of race on these endpoints, while controlling for baseline demographics and comorbidities.

RESULTS A total of 333 patients met the inclusion and exclusion criteria: 148 (44.44\%) white/Caucasian, $123(36.94 \%)$ black/African American, 54 (16.22\%) Hispanic/Latinx, and 8 (2.40\%) Asian. African American patients were sent to immediate care and rehabilitation significantly less often than Caucasian patients (RR $0.17[95 \% \mathrm{Cl} 0.04-0.71]$ ). There were no significant differences in mortality, length of stay, rates of surgical intervention, or total hospital charges among any of the racial groups.

CONCLUSIONS The authors' findings suggest that racial disparities in inpatient cranial trauma care and outcomes may not be as prevalent as previously thought. In fact, the disparities seen were only in disposition. More research is needed to further elucidate and address disparities within this population, particularly those that may exist prior to, and after, hospitalization.

https://thejns.org/doi/abs/10.3171/2019.8.FOCUS19484

KEYWORDS gunshot wounds to the head; racial disparities; mortality; discharge disposition; rehabilitation

$\mathrm{R}$ ACIAL disparities in healthcare access and treatment outcomes have been well established by existing literature. ${ }^{2,19}$ Such inequities in care are seen in a wide array of inpatient settings, ranging from cardiac interventions to multiple myeloma treatment to management of traumatic brain injury (TBI) ${ }^{6,9,12}$ This suggests a pervasive nature of these disparities, further heightening the importance of characterizing and addressing this issue in today's healthcare system. In addition to affecting acute patient care, race and ethnicity also seem to play a role in long-term functional health outcomes and mortality. Minority patients have been shown to have significantly higher mortality rates as well as significantly worse long-term results after TBI, for instance., ${ }^{3,20}$ Moreover, it has been demonstrated that minority patients are less likely to be placed in rehabilitation after sustaining TBI or other severe trauma.,19 Many factors may contribute to such disparities, including insurance status and other societal aspects. ${ }^{10}$ Despite these findings, recent investigations have demonstrated that acute care inequity may not be as significant as previously thought. One literature review examining outcomes of life-threatening injuries found no significant relationship between race and injury morbidity or mortality. ${ }^{16}$ Additional studies have revealed no correlation between race and mortality or treatment outcome, suggesting that it is not a significant predictor of acute care results. ${ }^{8,11,15}$ These inconclusive findings indicate the need for further research in order to better characterize the relationship between race and acute care treatment and outcomes. 
One area of trauma care that has not been extensively studied in this context is that of cranial trauma, specifically gunshot wounds. Gun violence is a serious healthcare epidemic, both in the United States and worldwide. In 2017, there were 39,773 firearm-related deaths in the United States. ${ }^{4}$ Gunshots rank among the top 2 most common causes of penetrating cranial wounds in the United States, next to stabbings. ${ }^{8}$ Mortality rates of gunshot wounds to the head $(\mathrm{GWH})$ are extremely high, with an estimated $90 \%$ of cases being fatal. Of patients who arrive to the hospital, approximately $50 \%$ die in the emergency department. ${ }^{5,18}$ As such, providing the best and most equitable care to those affected by this trauma is extremely important. Previous studies have focused on the demographics and mortality rates of patients suffering from GWH, concentrating less on treatment itself and favorability of discharge. This study examines whether racial disparities exist in the inpatient management and treatment outcomes among patients presenting with GWH.

\section{Methods}

The Nationwide (National) Inpatient Sample (NIS) was queried for the years 2012 to 2016 to identify all unique discharges associated with GWH. Maintained by the AHRQ (Agency for Healthcare Research and Quality), a subsidiary of the CMS (Centers for Medicare \& Medicaid Services), the NIS is the largest all-payer patient database in the United States, encompassing a 20\% sample of all hospitalizations across 47 states. Each record within the NIS represents a unique hospital stay, with approximately 8 million recorded per year, and contains patient demographics, comorbid conditions, Diagnosis Related Group (DRG), inpatient events (e.g., all-cause mortality, discharge disposition, surgical intervention), hospital charges, length of stay, and administrative codes for primary and secondary diagnoses and procedures, which are listed according to the ICD-9-CM and ICD-10-CM codes.

\section{Patient Selection}

Discharges from the NIS were included in the study if their first listed diagnosis (primary diagnosis) was an open wound of the head, defined by ICD-9 code $873 *^{*}$ or ICD-10 code S01.*, and if the patient's race was listed as white/Caucasian, black/African American, Hispanic/ Latinx, or Asian/Pacific Islander. ICD-9-CM and ICD-10$\mathrm{CM}$ external causes of injury codes were then utilized to identify those open wounds that were caused by firearms. The aforementioned codes encompassed assault-related firearm injuries (ICD-9-CM codes E965.0-E965.4 and ICD-10-CM codes X93-X95) as well as those that were unintentional (E922.0-E922.9, W32-34), self-inflicted (E955.0-E955.4, X72-74), inflicted by law enforcement (E970, Y350), and terrorism-related (E985.0-E985.4, Y384). Wounds of undetermined intent were also included in the study, designated by ICD-9-CM and ICD-10-CM codes E985.0-E985.4 and Y22-24, respectively.

\section{Endpoints}

The primary endpoints of this study were all-cause mortality, receipt of surgery, days from admission to ini- tial intervention, discharge disposition, length of hospital stay, and total hospital charges.

\section{Statistical Analysis}

The chi-square test (for categorical/nominal variables) and t-test (for continuous/numeric variables) were employed to assess baseline differences among the 4 racial/ ethnic groups of this study. These variables include sex, age, primary payer, hospital location, and prevalence of comorbid conditions. Endpoints were then assessed for the racial groups in pairs (e.g., Caucasian vs African American, Caucasian vs Hispanic) using 1:1 propensity score matching with the $k$-nearest neighbors method to control for demographics, morbidity, and severity of initial presentation. Throughout the study, Mann-Whitney U-tests were utilized in place of t-tests for interval and continuous variables that were not deemed normally distributed. A 2-tailed $p<0.05$ was utilized for determination of statistical significance. All analyses were conducted using R version 3.5.2 (r-project.org).

\section{Results}

A total of 333 patients meeting inclusion criteria were identified. Patient characteristics are presented in Table 1. These factors were controlled for in subsequent analysis using propensity score matching. Additionally, all variables were controlled for age, sex, location, cause of injury, and insurance status. Ethnic groups were compared in pairs, as demonstrated in Tables 2-4. However, due to the relative lack of Asian patients within the NIS database who met this study's inclusion criteria and a resulting inability to adequately control for all baseline variables with respect to other racial groups, we did not complete analyses with this group.

Our findings reveal that African American patients were sent to immediate care and rehabilitation significantly less than Caucasian patients (RR 0.17 [95\% CI 0.04-0.71]). Although not significant, African American patients were more likely to be sent home than Caucasian patients (RR 1.13 [95\% CI 0.89-1.45]). No significant difference in discharge disposition was demonstrated between the other ethnic pairings. Of note, there were no significant differences in mortality, length of stay, or rate of surgical intervention among any of the racial group pairings. Furthermore, we found no significant disparity in charges from the hospital stay between different ethnic groups.

\section{Discussion}

In this study, we found no significant variation among racial/ethnic groups in mortality rate, length of hospital stay, or surgical rate after GWH. Caucasian patients were more likely to be sent to immediate care and rehabilitation than African American patients; however, no significant difference in discharge disposition was apparent between other racial pairings. All other variables examined in our analysis failed to reveal meaningful discrepancies among the racial/ethnic groups. As such, these results support previous findings that these disparities in cranial trauma 
TABLE 1. Patient demographics

\begin{tabular}{|c|c|c|c|c|c|}
\hline & White $(n=148)$ & Black $(n=123)$ & Hispanic $(n=54)$ & Asian $(\mathrm{n}=8)$ & $p$ Value \\
\hline Mean age (SD), yrs & $40.48(20.16)$ & $27.58(10.79)$ & $23.78(11.96)$ & $25.88(17.23)$ & $<0.001$ \\
\hline Female sex & $20(13.51 \%)$ & $26(21.14 \%)$ & $9(16.67 \%)$ & $3(37.50 \%)$ & 0.171 \\
\hline Payer & & & & & $<0.001$ \\
\hline Medicare & $24(16.22 \%)$ & $3(2.44 \%)$ & $0(0.00 \%)$ & $0(0.00 \%)$ & \\
\hline Medicaid & $26(17.57 \%)$ & $45(36.59 \%)$ & $18(33.33 \%)$ & $4(50.00 \%)$ & \\
\hline Private insurance & $44(29.73 \%)$ & $25(20.33 \%)$ & $14(25.93 \%)$ & $1(12.50 \%)$ & \\
\hline Self-pay & $37(25.00 \%)$ & $33(26.83 \%)$ & $15(27.78 \%)$ & $3(37.50 \%)$ & \\
\hline No charge & $2(1.35 \%)$ & $6(4.88 \%)$ & $1(1.85 \%)$ & $0(0.00 \%)$ & \\
\hline Other & $15(10.14 \%)$ & $11(8.94 \%)$ & $6(11.11 \%)$ & $0(0.00 \%)$ & \\
\hline Hospital location & & & & & 0.088 \\
\hline Rural & $5(3.38 \%)$ & $1(0.81 \%)$ & $0(0.00 \%)$ & $0(0.00 \%)$ & \\
\hline Urban, teaching & $20(13.51 \%)$ & $11(8.94 \%)$ & $12(22.22 \%)$ & $0(0.00 \%)$ & \\
\hline Urban, non-teaching & $123(83.11 \%)$ & $111(90.24 \%)$ & $42(77.78 \%)$ & $8(100.00 \%)$ & \\
\hline \multicolumn{6}{|l|}{ Comorbidities } \\
\hline AIDS & $0(0.00 \%)$ & $0(0.00 \%)$ & $0(0.00 \%)$ & $0(0.00 \%)$ & $>0.99$ \\
\hline Alcohol use & $20(23.81 \%)$ & $6(7.23 \%)$ & $3(7.32 \%)$ & $0(0.00 \%)$ & 0.006 \\
\hline Anemia & $2(2.38 \%)$ & $1(1.20 \%)$ & $2(4.87 \%)$ & $0(0.00 \%)$ & 0.628 \\
\hline Coagulopathy & $1(1.19 \%)$ & $0(0.00 \%)$ & $1(2.44 \%)$ & $0(0.00 \%)$ & 0.597 \\
\hline $\mathrm{CHF}$ & $0(0.00 \%)$ & $0(0.00 \%)$ & $0(0.00 \%)$ & $0(0.00 \%)$ & $>0.99$ \\
\hline COPD & $5(5.95 \%)$ & $3(3.61 \%)$ & $2(4.88 \%)$ & $0(0.00 \%)$ & 0.858 \\
\hline Depression & $13(15.48 \%)$ & $1(1.20 \%)$ & $1(2.44 \%)$ & $0(0.00 \%)$ & 0.002 \\
\hline Diabetes & $3(3.57 \%)$ & $4(4.82 \%)$ & $0(0.00 \%)$ & $0(0.00 \%)$ & 0.532 \\
\hline Drug abuse & $9(10.71 \%)$ & $5(6.02 \%)$ & $6(14.63 \%)$ & $1(12.50 \%)$ & 0.381 \\
\hline Electrolyte disorders & $8(9.52 \%)$ & $7(8.43 \%)$ & $4(9.76 \%)$ & $0(0.00 \%)$ & 0.899 \\
\hline HTN & $1(1.19 \%)$ & $9(10.84 \%)$ & $2(4.88 \%)$ & $1(12.50 \%)$ & 0.257 \\
\hline Hypothyroidism & $1(1.19 \%)$ & $0(0.00 \%)$ & $0(0.00 \%)$ & $0(0.00 \%)$ & 0.672 \\
\hline Liver disease & $0(0.00 \%)$ & $0(0.00 \%)$ & $0(0.00 \%)$ & $0(0.00 \%)$ & $>0.99$ \\
\hline Lymphoma & $0(0.00 \%)$ & $0(0.00 \%)$ & $0(0.00 \%)$ & $0(0.00 \%)$ & $>0.99$ \\
\hline Metastatic cancer & $1(1.19 \%)$ & $0(0.00 \%)$ & $0(0.00 \%)$ & $0(0.00 \%)$ & 0.672 \\
\hline Neurological disorder & $7(8.33 \%)$ & $1(1.20 \%)$ & $0(0.00 \%)$ & $0(0.00 \%)$ & 0.043 \\
\hline Obesity & $3(3.57 \%)$ & $2(2.41 \%)$ & $0(0.00 \%)$ & $0(0.00 \%)$ & 0.647 \\
\hline Paralysis & $2(2.38 \%)$ & $0(0.00 \%)$ & $0(0.00 \%)$ & $0(0.00 \%)$ & 0.376 \\
\hline PVD & $1(1.19 \%)$ & $0(0.00 \%)$ & $0(0.00 \%)$ & $0(0.00 \%)$ & 0.672 \\
\hline Psychosis & $13(15.48 \%)$ & $2(2.41 \%)$ & $3(7.32 \%)$ & $0(0.00 \%)$ & 0.020 \\
\hline Renal failure & $0(0.00 \%)$ & $1(1.20 \%)$ & $0(0.00 \%)$ & $0(0.00 \%)$ & 0.665 \\
\hline Rheumatoid arthritis & $0(0.00 \%)$ & $0(0.00 \%)$ & $0(0.00 \%)$ & $0(0.00 \%)$ & $>0.99$ \\
\hline Tumor & $1(1.19 \%)$ & $0(0.00 \%)$ & $0(0.00 \%)$ & $0(0.00 \%)$ & 0.672 \\
\hline Peptic ulcer disease & $0(0.00 \%)$ & $0(0.00 \%)$ & $0(0.00 \%)$ & $0(0.00 \%)$ & $>0.99$ \\
\hline Valvular disease & $0(0.00 \%)$ & $0(0.00 \%)$ & $0(0.00 \%)$ & $0(0.00 \%)$ & $>0.99$ \\
\hline Weight loss & $2(2.38 \%)$ & $0(0.00 \%)$ & $1(2.44 \%)$ & $0(0.00 \%)$ & 0.543 \\
\hline
\end{tabular}

$\mathrm{CHF}=$ congestive heart failure; $\mathrm{COPD}=$ chronic obstructive pulmonary disease; $\mathrm{HTN}=$ hypertension; $\mathrm{PVD}=$ peripheral vascular disease.

Boldface type indicates statistical significance.

care and mortality may not be as significant as some studies have suggested.

Jesin et al. examined predictors of mortality and the role of race in outcomes of head and neck trauma. Although they demonstrated African American and Hispanic individuals sustain significantly more gunshot wounds than Caucasians, there were no significant differences in length of stay or mortality. ${ }^{11}$ This suggests that treatment biases in the acute care setting may not be particularly substantial. Another study conducted by Crutcher et al. echoes these findings. In their investigation of epidemiological characteristics and racial differences in patients with gunshot wounds, they showed that race was not a predictor of survival outcome. ${ }^{8}$ 
TABLE 2. Management and outcomes of Caucasian versus African American patients

\begin{tabular}{|c|c|c|c|c|}
\hline & White $(n=57)$ & Black $(n=57)$ & $\mathrm{RR}(95 \% \mathrm{Cl})$ & $\mathrm{p}$ Value \\
\hline Died & $4(7.02 \%)$ & $3(5.26 \%)$ & $0.75(0.18-3.20)$ & $>0.99$ \\
\hline Underwent surgical procedure & $34(59.65 \%)$ & $33(57.89 \%)$ & $0.97(0.71-1.32)$ & $>0.99$ \\
\hline Mean days from admission to procedure (SD) & $0.81(2.77)$ & $0.42(0.89)$ & & 0.321 \\
\hline \multicolumn{5}{|l|}{ Discharge disposition } \\
\hline Home & $37(64.91 \%)$ & $42(73.68 \%)$ & $1.13(0.89-1.45)$ & \multirow{6}{*}{0.026} \\
\hline Short-term hospital & $3(5.26 \%)$ & $4(7.02 \%)$ & $1.33(0.21-5.69)$ & \\
\hline Skilled nursing/intermediate care/rehabilitation & $12(21.05 \%)$ & $2(3.51 \%)$ & $0.17(0.04-0.71)$ & \\
\hline Home healthcare & $0(0.00 \%)$ & $5(8.77 \%)$ & & \\
\hline Left AMA & $1(1.75 \%)$ & $1(1.75 \%)$ & $1.00(0.06-15.60)$ & \\
\hline Died & $4(7.02 \%)$ & $3(5.26 \%)$ & $0.75(0.18-3.20)$ & \\
\hline Mean length of stay (SD), days & $5.96(9.82)$ & $3.37(4.34)$ & & 0.074 \\
\hline Mean charges (SD), USD & $68,923.51(88,060.84)$ & $55,269.00(57,138.44)$ & & 0.329 \\
\hline Mean charges per day (SD), USD & $19,786.00(18,192.13)$ & $17,646.66(12,630.46)$ & & 0.495 \\
\hline
\end{tabular}

AMA = against medical advice; USD = US dollars

Boldface type indicates statistical significance.

Earlier studies investigating race and ethnicity in relation to acute care post-GWH have further supported these findings of insignificant racial bias. For example, Millham and Jain found no mortality differences based on race after GWH. ${ }^{15}$ However, they also demonstrated that African American and Hispanic patients had shorter hospital stays and were more likely to be transferred to postacute care than Caucasian patients. This result differs from the findings of this study, which revealed no significant differences in length of stay as well as higher rates of immediate care and rehabilitation among Caucasians.

As demonstrated, our results both support and refute previous findings in several ways. One insightful conclusion of this study was the lack of significant differences between length of stay, mortality, and surgical rate among ethnic groups. This suggests that in the setting of GWH, racial biases may not play a significant role in these outcomes. We did, however, find a significant discrepancy between African American and Caucasian patients in terms of discharge disposition. This result is supported by a study conducted by Meagher et al., which showed that adult Hispanic and African American patients were less likely to receive intensive rehabilitation than their Caucasian counterparts after TBI. ${ }^{12}$ Several other investigations examining post-TBI care have further enhanced this finding. A study conducted by Asemota et al. showed that, compared with insured white patients, insured African American patients were less likely to be discharged to rehabilitation centers. ${ }^{2}$ Furthermore, Bowman et al. observed a decreased proportion of Hispanic and African American patients discharged to a rehabilitation center after TBI compared with Caucasians. ${ }^{3}$ Additionally, studies have revealed racial/ethnic differences in follow-up after discharge. Chun Fat et al. examined disparities in postdischarge healthcare utilization after trauma and found that African American patients were less likely to use rehabilitation services and had fewer injury-related outpatient visits after discharge. ${ }^{7}$ Our study seems to be the first to

TABLE 3. Management and outcomes of Caucasian versus Hispanic patients

\begin{tabular}{|c|c|c|c|c|}
\hline & White $(n=35)$ & Hispanic $(n=35)$ & $\mathrm{RR}(95 \% \mathrm{Cl})$ & $\mathrm{p}$ Value \\
\hline Died & $1(2.86 \%)$ & $0(0.00 \%)$ & 0.00 (0.00-infinity) & 0.314 \\
\hline Underwent surgical procedure & $19(54.29 \%)$ & $19(54.29 \%)$ & $1.00(0.65-1.54)$ & $>0.99$ \\
\hline Mean days from admission to procedure (SD) & $0.46(0.92)$ & $0.69(1.71)$ & & 0.545 \\
\hline \multicolumn{5}{|l|}{ Discharge disposition } \\
\hline Home & $27(77.14 \%)$ & $30(85.71 \%)$ & $1.11(0.89-1.39)$ & \multirow{6}{*}{0.556} \\
\hline Short-term hospital & $2(5.71 \%)$ & $2(5.71 \%)$ & $1.00(0.15-6.71)$ & \\
\hline Skilled nursing/intermediate care/rehabilitation & $4(11.42 \%)$ & $1(2.86 \%)$ & $0.25(0.03-2.13)$ & \\
\hline Home healthcare & $0(0.00 \%)$ & $1(2.86 \%)$ & & \\
\hline Left AMA & $1(2.86 \%)$ & $1(2.86 \%)$ & $1.00(0.07-15.36)$ & \\
\hline Died & $1(2.86 \%)$ & $0(0.00 \%)$ & 0.00 (0.00-infinity) & \\
\hline Mean length of stay (SD), days & $4.20(5.71)$ & $3.00(3.08)$ & & 0.279 \\
\hline Mean charges (SD), USD & $45,805.74(32,724.50)$ & $54,385.03(39,298.44)$ & & 0.325 \\
\hline Mean charges per day (SD), USD & $18,168.09(18,583.47)$ & $27,438.80(34,761.28)$ & & 0.184 \\
\hline
\end{tabular}


TABLE 4. Management and outcomes of African American versus Hispanic patients

\begin{tabular}{lcccc}
\hline & Black $(\mathrm{n}=35)$ & Hispanic $(\mathrm{n}=35)$ & $\mathrm{RR}(95 \%$ Cl) & $\mathrm{p} \mathrm{Value}$ \\
\hline Died & $2(5.71 \%)$ & $0(0.00 \%)$ & $0.00(0.00$-infinity) & 0.493 \\
\hline Underwent surgical intervention & $16(45.71 \%)$ & $19(54.29 \%)$ & $1.19(0.74-1.90)$ & 0.633 \\
\hline Mean days from admission to procedure (SD) & $0.40(0.81)$ & $0.69(1.71)$ & & 0.377 \\
\hline Discharge disposition & & & \\
\hline Home & $25(71.43 \%)$ & $30(85.71 \%)$ & $1.20(0.94-1.54)$ \\
\hline Short-term hospital & $3(8.57 \%)$ & $2(5.71 \%)$ & $0.67(0.12-3.75)$ \\
\hline Skilled nursing/intermediate care/rehabilitation & $2(5.71 \%)$ & $1(2.86 \%)$ & $0.50(0.05-5.27)$ & 0.651 \\
\hline Home healthcare & $2(5.71 \%)$ & $1(2.86 \%)$ & $0.50(0.05-5.27)$ \\
\hline Left AMA & $1(2.86 \%)$ & $1(2.86 \%)$ & $1.00(0.07-15.36)$ \\
\hline Died & $2(5.71 \%)$ & $0(0.00 \%)$ & $0.00(0.00-$ infinity) & \\
\hline Mean length of stay (SD), days & $3.54(4.79)$ & $3.00(3.08)$ & & 0.575 \\
\hline Mean charges (SD), USD & $55,725.77(62,210.14)$ & $54,385.03(39,298.44)$ & & 0.915 \\
\hline Mean charges per day (SD), USD & $18,297.08(12,199.22)$ & $27,438.80(34,761.28)$ & & 0.163 \\
\hline
\end{tabular}

reproduce this finding of a racially based discrepancy in discharge deposition specifically in the setting of GWH. One possible explanation for this outcome may lie in disparities among rehabilitation facilities and nursing homes. Facilities in racial minority neighborhoods have been shown to be of substantially lower quality when compared with mostly Caucasian neighborhoods. A study conducted by Yuan et al. found that nursing homes located in communities with lower socioeconomic statuses were associated with overall lower star ratings, staff ratings, and quality ratings. ${ }^{21}$ As a result, residents in disadvantaged areas experience disparities in accessing highly rated nursing home care. Similarly, socioeconomically disadvantaged counties may lack sufficient resources to adequately staff rehabilitation care facilities and provide the quality of care that meets industry standards. These factors may potentially sway patients' decisions regarding care after discharge. If an individual does not foresee receiving optimum care at the closest rehabilitation facility, he or she may not be inclined to pursue treatment there.

It is important to note that our analysis controlled for other socioeconomic baseline characteristics, such as patient insurance status and hospital teaching status. Differences in these factors are often related to one's racial or ethnic background and may simultaneously influence healthcare access to the extent that it often confounds similar analyses. ${ }^{13,17}$ For example, in their study of inpatient trauma mortality, Mikhail et al. found that insurance type was associated with mortality rate, while race was not. ${ }^{14}$ After controlling for insurance type in the current study, we found no significant difference in mortality after GWH. This suggests that insurance status plays a role in disparities in care, and, when controlled for in analysis, many initial disparities that appeared to be based on race and ethnicity became insignificant. Therefore, a driving factor in previously suggested racial biases in healthcare after trauma may be insurance status, among other socioeconomic characteristics associated with race, rather than race alone. If this were true, it follows that standardization of insurance coverage may eliminate many of the barriers associated with the minority groups' collective access to high-value trauma care. This is supported by the conclusions of Akande et al., who demonstrated that Medicaid expansion in its 1st year decreased racial and socioeconomic disparities in access to rehabilitation. ${ }^{1}$ Taken together, these results indicate the important role that insurance status and socioeconomic barriers play in inciting treatment disparities between ethnic groups within the United States.

Further research characterizing racial biases in cranial trauma care is necessary in order to understand this relationship to a greater extent. Our findings suggest, in general, that there is a relative lack of racial disparities in cranial trauma care after GWH in comparison with previous speculation. Additional studies examining whether these findings extend to other cranial trauma injuries are also warranted. As noted, cranial trauma is extremely fatal. Thus, it is critically important to maximize quality of care in a nonbiased manner in order to increase survival and improve outcomes for all patients affected by this injury.

\section{Limitations}

Limitations in this study include underrepresentation from racial groups aside from Caucasian, African American, and Hispanic individuals. Our original data contained outcomes from Asian patients; however, there were insufficient numbers of patients from this group to include in our analysis. Investigations comparing more ethnic groups may help provide further insight on the nature of bias in cranial trauma care. For this to be accomplished, larger and more diverse population samples should be studied. Similarly, these results could be stratified by county, perhaps shining light on the effects of overall racial distribution or socioeconomic status of various areas on disparities in care.

\section{Conclusions}

This study provides an examination of racial disparities in inpatient management and outcomes from GWH. It identified significant differences between ethnic groups in discharge disposition but not in overall inpatient all-cause 
mortality, length of stay, or associated hospital charges. Our findings suggest that racial disparities in cranial trauma care and outcomes may not be as prevalent as previously thought when controlling for demographics, socioeconomic disposition, and major medical comorbidities. Although we did find that African American patients were less likely than Caucasian patients to be sent to a rehabilitation facility, we believe that factors other than physician bias may contribute to this occurrence. These results add to the collective investigation of racial disparities in trauma care; additional studies at the state and national level are needed to further enhance our understanding of this extremely important relationship.

\section{References}

1. Akande M, Minneci PC, Deans KJ, Xiang H, Chisolm DJ, Cooper JN: Effects of Medicaid expansion on disparities in trauma care and outcomes in young adults. J Surg Res 228:42-53, 2018

2. Asemota AO, George BP, Cumpsty-Fowler CJ, Haider AH, Schneider EB: Race and insurance disparities in discharge to rehabilitation for patients with traumatic brain injury. J Neurotrauma 30:2057-2065, 2013

3. Bowman SM, Martin DP, Sharar SR, Zimmerman FJ: Racial disparities in outcomes of persons with moderate to severe traumatic brain injury. Med Care 45:686-690, 2007

4. Bulger EM, Kuhls DA, Campbell BT, Bonne S, Cunningham RM, Betz M, et al: Proceedings from the Medical Summit on Firearm Injury Prevention: a public health approach to reduce death and disability in the US. J Am Coll Surg 229:415-430.e12, 2019

5. Cavaliere R, Cavenago L, Siccardi D, Viale GL: Gunshot wounds of the brain in civilians. Acta Neurochir (Wien) 94:133-136, 1988

6. Chen J, Rathore SS, Radford MJ, Wang Y, Krumholz HM: Racial differences in the use of cardiac catheterization after acute myocardial infarction. N Engl J Med 344:1443-1449, 2001

7. Chun Fat S, Herrera-Escobar JP, Seshadri AJ, Al Rafai SS, Hashmi ZG, de Jager E, et al: Racial disparities in post-discharge healthcare utilization after trauma. Am J Surg [epub ahead of print], 2019

8. Crutcher CL II, Fannin ES, Wilson JD: Racial disparities in cranial gunshot wounds: intent and survival. J Racial Ethn Health Disparities 3:687-691, 2016

9. Ganguly S, Mailankody S, Ailawadhi S: Many shades of disparities in myeloma care. Am Soc Clin Oncol Educ Book 39:519-529, 2019

10. Haider AH, Chang DC, Efron DT, Haut ER, Crandall M, Cornwell EE III: Race and insurance status as risk factors for trauma mortality. Arch Surg 143:945-949, 2008

11. Jesin M, Rashewsky S, Shapiro M, Tobler W, Agarwal S, Burke P, et al: Predictors of mortality, hospital utilization, and the role of race in outcomes in head and neck trauma. Oral Surg Oral Med Oral Pathol Oral Radiol 121:12-16, 2016

12. Meagher AD, Beadles CA, Doorey J, Charles AG: Racial and ethnic disparities in discharge to rehabilitation following traumatic brain injury. J Neurosurg 122:595-601, 2015

13. Meghani SH, Chittams J: Controlling for socioeconomic status in pain disparities research: all-else-equal analysis when "all else" is not equal. Pain Med 16:2222-2225, 2015

14. Mikhail JN, Nemeth LS, Mueller M, Pope C, NeSmith EG, Wilson KL, et al: The association of race, socioeconomic status, and insurance on trauma mortality. J Trauma Nurs 23:347-356, 2016

15. Millham F, Jain NB: Are there racial disparities in trauma care? World J Surg 33:23-33, 2009

16. NeSmith EG: Racial disparities in acute outcomes of lifethreatening injury. J Nurs Scholarsh 38:241-246, 2006

17. Ng DK, Brotman DJ, Lau B, Young JH: Insurance status, not race, is associated with mortality after an acute cardiovascular event in Maryland. J Gen Intern Med 27:1368-1376, 2012

18. Shaffrey ME, Polin RS, Phillips CD, Germanson T, Shaffrey CI, Jane JA: Classification of civilian craniocerebral gunshot wounds: a multivariate analysis predictive of mortality. $\mathbf{J}$ Neurotrauma 9 (Suppl 1):S279-S285, 1992

19. Shafi S, de la Plata CM, Diaz-Arrastia R, Bransky A, Frankel $\mathrm{H}$, Elliott AC, et al: Ethnic disparities exist in trauma care. J Trauma 63:1138-1142, 2007

20. Shafi S, Marquez de la Plata C, Diaz-Arrastia R, Shipman K, Carlile M, Frankel H, et al: Racial disparities in long-term functional outcome after traumatic brain injury. J Trauma 63:1263-1270, 2007

21. Yuan Y, Louis C, Cabral H, Schneider JC, Ryan CM, Kazis LE: Socioeconomic and geographic disparities in accessing nursing homes with high star ratings. J Am Med Dir Assoc 19:852-859.e2, 2018

\section{Disclosures}

The authors report no conflict of interest concerning the materials or methods used in this study or the findings specified in this paper.

\section{Author Contributions}

Conception and design: Mehta, Chiu. Acquisition of data: Chiu. Analysis and interpretation of data: Chiu. Drafting the article: Chiu, Fuentes. Critically revising the article: Mehta, Chiu. Reviewed submitted version of manuscript: Mehta, Chiu. Approved the final version of the manuscript on behalf of all authors: Mehta. Statistical analysis: Chiu. Administrative/technical/material support: Mehta. Study supervision: Mehta.

\section{Correspondence}

Ankit I. Mehta: University of Illinois at Chicago, IL. ankitm@uic. edu. 